\title{
Experimental platform tests for setting performances of distance protection installed in Biskra-Batna of the Algerian transmission line
}

\author{
Yassine Khelil $^{1}$, Belkacem Mahdad ${ }^{2}$, Abdelhak Tobbeche ${ }^{3}$ \\ ${ }^{1,2}$ Department of Electrical Engineering, Faculty of Science and Technology, University of Biskra, Algeria \\ ${ }^{3}$ GRTE, Sonelgaz Company, Algeria
}

\begin{tabular}{l} 
Article Info \\
\hline Article history: \\
Received Aug 23, 2020 \\
Revised Dec 16, 2020 \\
Accepted Feb 5, 2021 \\
\hline Keywords: \\
Digital relays \\
Distance protection \\
Fault currents \\
Micom P442 \\
Power system \\
Protection system
\end{tabular}

Corresponding Author:

Mahdad Belkacem Department of Electrical Engineering Faculty of Science and Technology University of Biskra, Algeria Email: belkacem.mahdad@univ-biskra.dz

\begin{abstract}
The modern power system is equipped with protection system based on advanced technology through the use of digital multifunction relay, control system and intelligent selectivity, whose purpose is to ensure maximum security and service continuity of protection relay in the presence of various fault currents. Distance protection is an important protection required in high voltage transmission lines. In this paper, experimental platform tests have been performed and proposed for setting and evaluation the performances of distance protection named Micom P442 installed in Biskra-Batna of the Algerian transmission power system. The performances of the distance protection have been evaluated under various short circuits. In this study, experimental result based single phase fault to ground is analysed and discussed. Experimental results based on the proposed platform tests in terms of precision in detecting faults at various locations and trigger times confirm the efficiency and particularity of the proposed experimental platform tests.
\end{abstract}

This is an open access article under the CC BY-SA license.

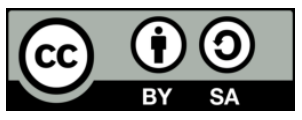

\section{INTRODUCTION}

To ensure reliable operation of modern power system in terms of power quality and service continuity it is mandatory to install an efficient power system protection. To ensure with efficacy this vital task, each power system's element must be protected and well coordinated. The various protective relays located in the network are normally coordinated using several types of selectivity such as time discrimination, current discrimination, logic selectivity or the combination between them. In general to ensure the basic selectivity, two protections are required, the primary protection must operate within its predetermined time, in case of failure of primary protection, the back-up protection must react after a delay time named security margin time [1]. Numeric distance protection is considered as a fundamental protection for large transmission line. The main advantage of installing distance protection in large transmission lines is related to its high ability to detect and eliminate faults at four regions. In practical situation, the coordination between zones is an important task to remove the faults by disconnecting the least possible part of the line to ensure service continuity. In the recent literature many strategies and simulators have been developed to ensure reliable operation of numeric distance protection. 
In [2], a methodology for evaluating distance relay transient performance based on extensive laboratory testing is presented. The performances of the proposed testing platform are validated and applied on a $345 \mathrm{kV}$ transmission line of interest to the Houston Lighting and Power Company (HL\&P). In [3], a novel scheme for transmission line fault detection using zone 3 and the transient components that are combined by using the state diagram is proposed. Simulation results prove the efficiency of the proposed strategy to relieve the maloperations that are caused by the heavy loading or the voltage instability associated with conventional distance relay. In [4], a study is proposed to show the load model effects on distance protective relay settings in Taipower's transmission system. In [5], an improved zone-3 distance protection based on adjacent relays data is proposed, the coordination strategy is capable of discriminating between the actual faults and power system stressed conditions. In [6], a study is presented to show the effect of renewable sources on the performances of distance protection.

A new algorithm has been developed to improve the detection of faulted phase selection and directionality on distance protection under a short circuit current fed by renewable energy sources. In [7], a control strategy is proposed to improve the performance of distance protection considering the effect of series compensation in heavily loaded transmission lines. In [8], a Mho type distance relay is proposed by using fuzzy logic to protect the transmission line and to defeat under and over-reach problems. In [9] a new approach for Mho relay algorithm in MATLAB based on fast Fourier transform algorithm (FFT) is proposed. The performance of the proposed numerical algorithm is validated on tested on simulated transmission line of Merowe-Atbara $500 \mathrm{KV}, 50 \mathrm{~Hz}$, and 236.7 KM using data generated by PSCAD/EMTDC. To increase the relaibility of transmission power system, authors in [10], proposed an interactive control strategy to improve the setting and coordination of distance relays. In [11], nonlinear multivariable optimization techniques have been used to improve the performance of distance relays in coordination with directional overcurrent. In [12], a simulation program-based MATLAB/Simulink is proposed to detect three zones using relays characyeristics, coordination of distance relays and cirduit breakers. In [13], a Mho distance relay simulation based on the phase comparison, technique using a typical electrical power systems analysissoftware.

Actually with the large integration of flexible AC transmission system (FACTS) system and renewable sources, the optimal location and coordination between various distance protection and other types of protection are a vital task to experts to ensure reliable exploitation of interconnected power systems. In [14], a qualitative study on the effects of thyristor controlled series capacitor (TCSC) on the distance protection strategies is proposed. In [15], an overview of adaptive overcurrent relay coordination in distribution electric networks in the presence of several distributed enrgy resources is proposed. In [16], the optimal coordination of directional overcurrent relays is studied and analysed in the presence of renewable energy sources, in [17], a method for protection of single-line-ground fault of distribution system with DG using distance relay and directional relay, in [18], a real-time modeling and testing of distance protection relay based on IEC 61850 protocol modélisation is proposed, and in [19], a distance relay-based phasor measurements for protection of transmission lines considering the integration and effect of of UPFC devices is studied and analysed.

The main objective and contribution of this paper compared to many developed techniques treating the setting and coordination of distance relays can be summarized as follows:

- An interactive experimental platform tests is proposed to evaluate the performances of various types of distance protection.

- The proposed experienatl strategy validated on numeric distance protection installed in a practical transmission line located at Biskra-Batna in the Algeria transmission power system.

- An efficient interactive program based Matlab desinged to optimally choose the best setting parameters of various types of relays.

The paper is organized as follows, in the first section, a critical review is established to well locate the best technical strategies to enhance the setting and coordination of distance relays and overcurrent relays. In the second section, a brief description of distance protection is introduced. In section III, the elements of the proposed experimental platform are presented and explained; and in section IV, many experimental tests have been suggested and applied to validate the performance of the proposed experimental testing platform in term of evaluation the efficiency of distance protection installed in practical transmission lines.

\section{PRINCIPLE OF DISTANCE PROTECTION}

Distance protection relay is based on estimating the ratio between the voltage ' $\mathrm{V}$ ' and the current ' $\mathrm{I}$ ' at the relaying point as shown in Figure 1. This ratio represents the impedance $\mathrm{Zf}$ of the faulty line between the relay location and the point of fault occurrence. The amount of impedance fault compared to the reference impedance (without fault) determines the required action to be taken by relay. In general distance protection designed to detect and eliminate faults at four regions. In practical situation, the coordination between zones 
is an important task to remove the faults by disconnecting the least possible part of the line to ensure service continuity. In this work and based on schematic representation of principle of distance protection shown in Figure 2, the configuration of the four protection zones are explained and the action to be taken by distance relay as primary as well as backup relay is discussed.

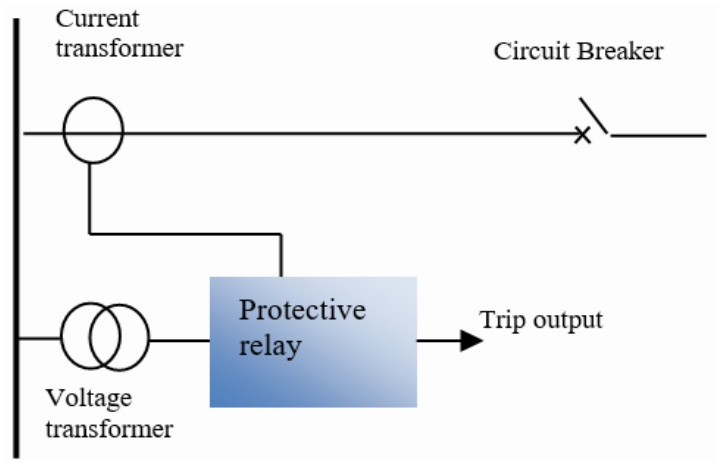

Figure 1. Basic elements of distance relay

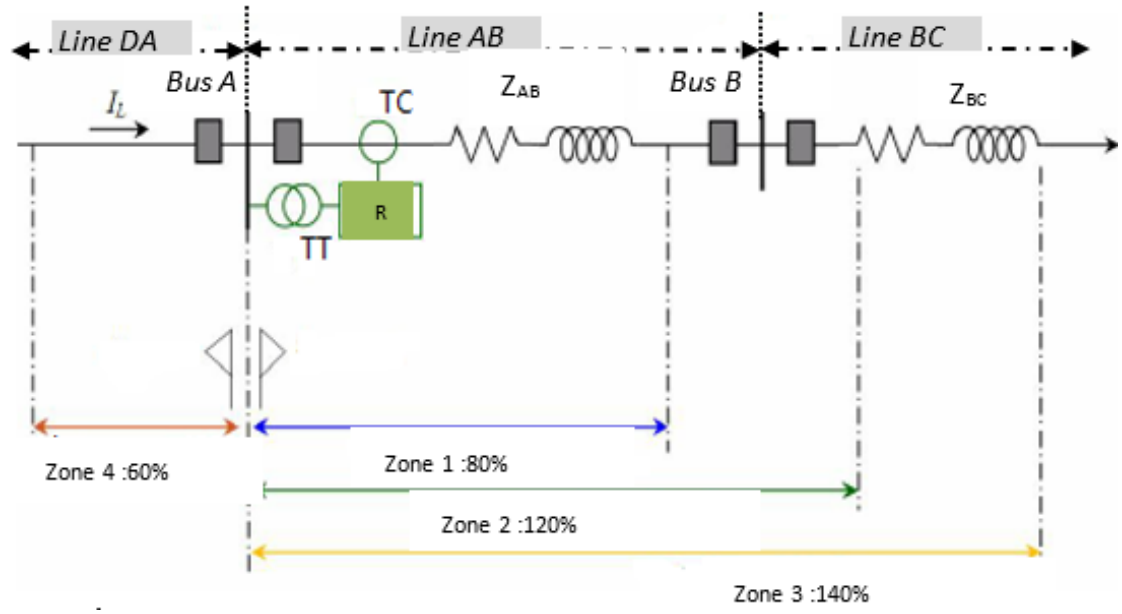

(a)

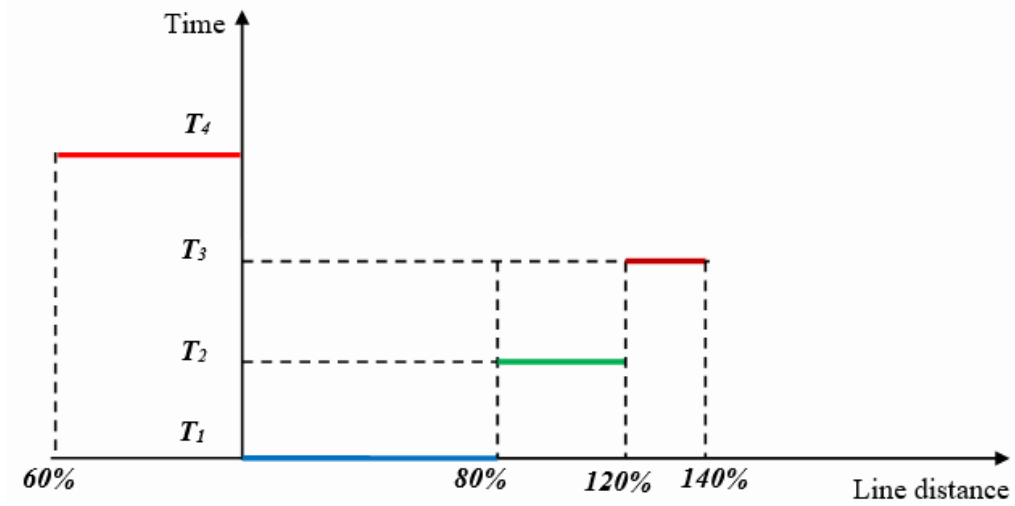

(b)

Figure 2. These figures are; (a) Principle of distance relay, (b) Relay operation time related to four zones

Based on the protection strategy adopted by GRTE at Sonelgaz Company, the adjustment of distance protection zones are described as follows:

- Zone 1: the impedance of the first zone is adjusted to $80 \%$ of the impedance of the principal line.

Experimental platform tests for setting performances of distance protection installed ... (Yassine Khelil) 
- Zone 2: the impedance of the second zone is adjusted to $100 \%$ of the impedance of principal line $+20 \%$ of the impedance of adjacent line.

- Zone 3: the impedance of the third zone is adjusted to $100 \%$ of the principal impedance line $+40 \%$ of the impedance of the adjacent line.

- Zone 4: the impedance of the fourth zone located at the left of the principal line is adjusted to $40 \%$ of the impedance.

\subsection{Description of experimental platform tests}

The schematic representation of the proposed experimental platform tests for distance protection evaluation is shown in Figure 3. As well shown in Figure 4, the elements of the experimental platform are described as follows:

- An OMICRON injection case type cmc356

- A distance protection (Micom p442)

- A variable continuous source (DC)

- A PC for simulation and communication with distance protection

- A circuit breaker associated with the distance protection

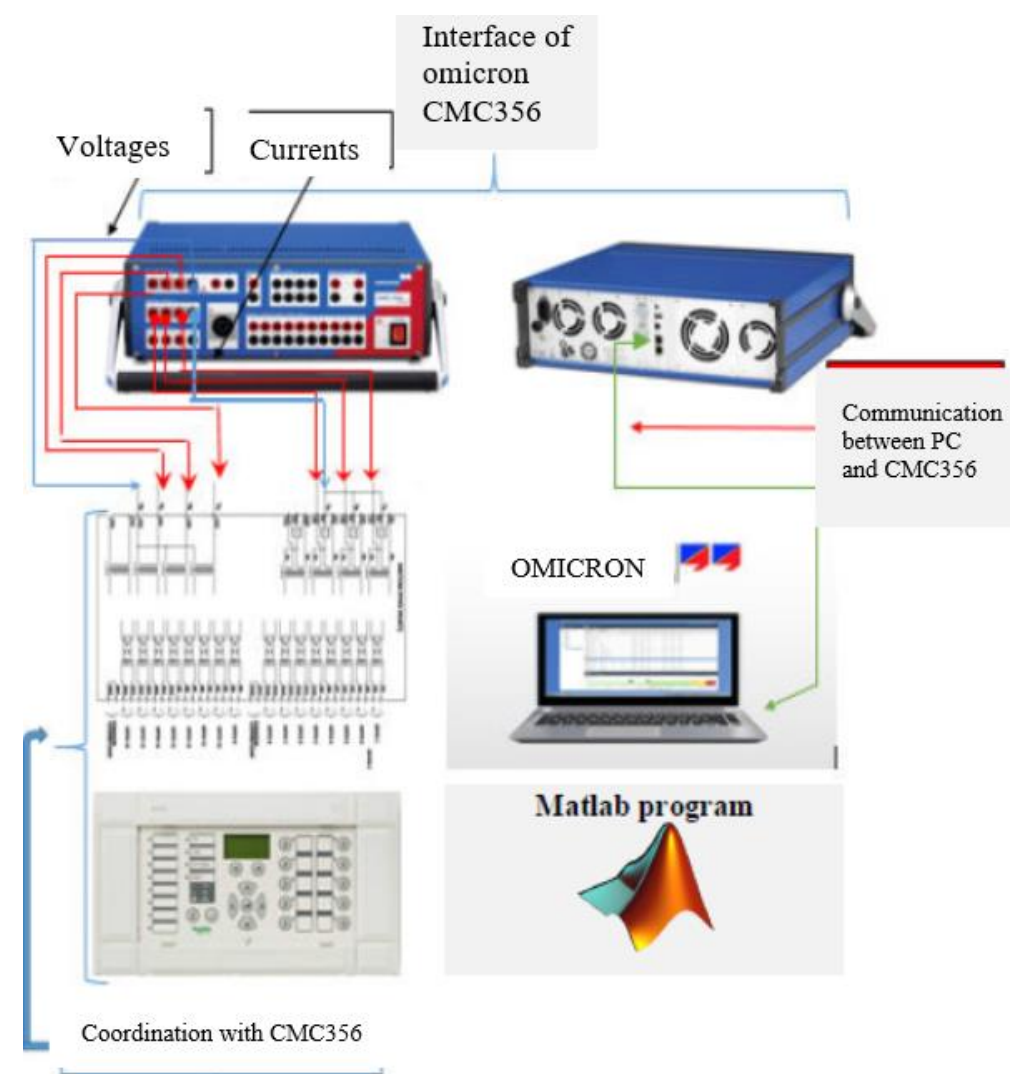

Figure 3. Schematic representation of the proposed experimental platform tests for distance protection evaluation

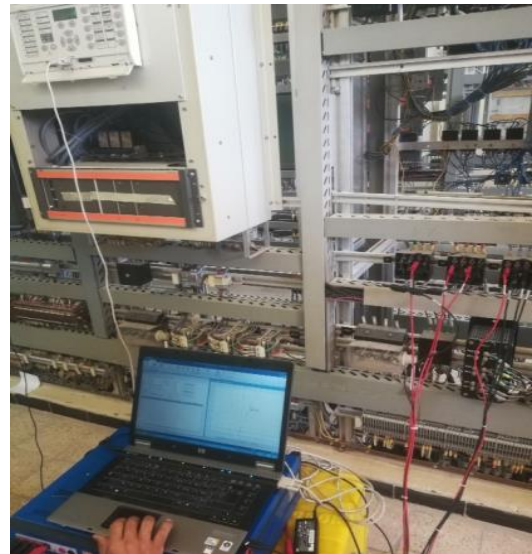

Figure 4. Experimental platform for distance protection tests implemnted in GRTE Company

\subsection{Distance protection (Micom P442)}

As well shown in Figure 5, the Micom P442 is a special remote protection relay designed for transmission lines protection. The present relay provides the full range of distance protection and has multi functions protection required to protect with efficacy long transmission lines. It includes several protective functions normally required for the protection of transmission lines:

- Fast trigger time

- Suitable for cables and overhead lines with or without compensation 
- Automatic reclosing in case of presence of fault

- Digital communication between relays for two or three substations

- Adjustable automatic recloser (ADT)

- Single-phase tripping and reclosing

\subsection{Injection module (CMC356)}

This module has been designed to elaborate fast and easy tests; it provides access to all currents and voltages generated and also allow reception of signals which indicate several statuses of the protection. So, the purpose of this module is to simulate and analysis the various faults affecting power transmission line. Figure 6 shows the typical injection module CMC356.

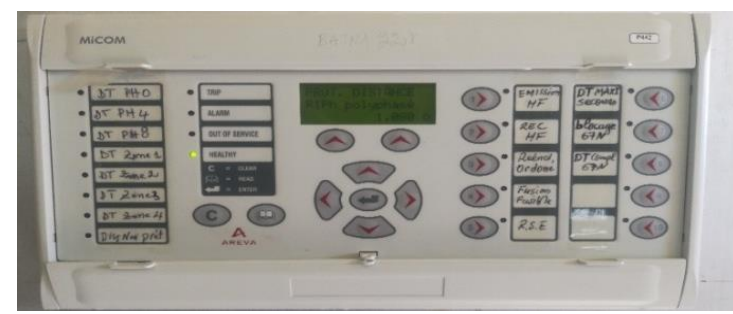

Figure 5. Distance protection (Micom P442)

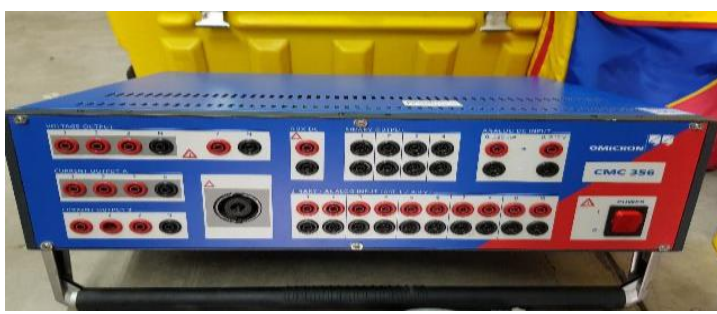

Figure 6. Injection case: omicron cmc356: Source GRTE company

\section{EXPERIMENTAL TESTS}

The proposed experimental platform tests validated on a practical transmission line Batna-Biskra. The technical data related to the transmission line are recapitulated in Table 1.

Table 1. Technical data for transmission line: Biskra-batna

\begin{tabular}{lcccccccc}
\hline & $\mathrm{X}$ & $\mathrm{R}$ & distance & $\mathrm{X}_{\text {sec }}$ & $\mathrm{R}_{\text {sec }}$ & $Z_{\text {sec }}$ & Angle in degree \\
\hline Biskra-Batna 220kv & $(\Omega / \mathrm{km})$ & $(\Omega / \mathrm{km})$ & $(\mathrm{km})$ & $(\Omega)$ & $(\Omega)$ & $(\Omega)$ & 78.31 \\
& $Z_{d}$ & 0.29 & 0.06 & & 16.02 & 3.32 & 16.36 & 77.68 \\
Batna-Ain Melila & $Z_{0}$ & 0.87 & 0.19 & 101.3 & 48.07 & 9.95 & 49.20 & 8.13 \\
Batna-Ain Melila & $Z_{d}$ & 0.29 & 0.06 & & 7.96 & 1.65 & 24.43 \\
\hline
\end{tabular}

\subsection{Distance protection configuration}

In this section a brief description about the adjustment of the parameters of distance protection are:

$\mathrm{Ku}=220000 / 100=2200$

$\mathrm{Ki}=1200 / 1 \mathrm{~A}=1200$

where, $\mathrm{Ku}, \mathrm{Ki}$ are the ratios of voltage transformer and current transformer, respectively.

$\mathrm{KZ}=2200 / 1200$

The following basic equations used to calculate the direct and homopolar component of resistance and reactance associated to a specified transmission line.

$$
\begin{aligned}
& R_{d-B T}=R_{d}-H T / K Z \\
& X_{d-B T}=R_{d}-H T /_{K Z} \\
& R_{O-B T}=R_{O}-H T /_{K Z} \\
& X_{O-B T}=X_{O}-H T /_{K Z} \\
& Z_{B T}=Z_{H T} / K Z
\end{aligned}
$$


where, $R_{d-B T} a n d X_{d-B T}$ are the direct component of resistance and reactance calculated in secondary side. $R_{o-}$ ${ }_{B T}$ and $X_{o-B T}$ are the homopolar component of resistance and reactance calculated in secondary side. In our test system we obtain:

$\mathrm{Z}_{\mathrm{d}-\mathrm{BT}}=\mathrm{Z}_{\mathrm{d}-\mathrm{HT}} / \mathrm{K}_{\mathrm{Z}}=3.23+\mathrm{j} 16.02 \Omega$, and $\mathrm{Z}_{\mathrm{d}-\mathrm{BT}}=9.95+\mathrm{j} 48.07 \Omega$

The absolute values of impedances related to four zones are calculated as follows:

Zone $1: \mathrm{Z} 1=0.8 . \mathrm{Z}_{\mathrm{d}-\mathrm{BT}}=0.8 * 16.36=13.09 \Omega$

Zone $2: \mathrm{Z} 2=\mathrm{Z}_{\mathrm{d}-\mathrm{BT}}+0.2 \mathrm{Z}_{\mathrm{d}-\mathrm{BT}}=19.64 \Omega$

Zone 3: $\mathrm{Z3}=\mathrm{Z}_{\mathrm{d}-\mathrm{BT}}+0.2 . \mathrm{Z}_{\mathrm{d}-\mathrm{BT}}=22.91 \Omega$

Zone 4: $\mathrm{Z} 4=0.4 . \mathrm{Z}_{\mathrm{d}-\mathrm{BT}}=6.55 \Omega$

The absolute values of impedance related to the four zones are recapitulated in Table 2.

Table 2. Calculated impedances of various protection zones

\begin{tabular}{ccccc}
\hline & $\begin{array}{c}\text { Zone 1 } \\
\text { upstream }\end{array}$ & $\begin{array}{c}\text { Zone 2 } \\
\text { upstream }\end{array}$ & $\begin{array}{c}\text { Zone 3 } \\
\text { upstream }\end{array}$ & $\begin{array}{c}\text { Zone 4 } \\
\text { downstream }\end{array}$ \\
\hline $\mathrm{Z}_{\mathrm{d}}(\Omega)$ & 13.09 & 19.64 & 22.91 & 6.55 \\
$\mathrm{R}_{\mathrm{Ph}}(\Omega)$ & 28.0 & 28.0 & 28.0 & 28.0 \\
$\mathrm{R}_{\mathrm{G}}(\Omega)$ & 35.0 & 35.0 & 35.0 & 35.0 \\
$\mathrm{KZ}$ & 0.67 & 0.67 & 0.67 & 0.67 \\
$\operatorname{Arg}(\mathrm{KZ})$ & -0.94 & -0.94 & -0.94 & -0.94 \\
$\mathrm{t}(\mathrm{s})$ & 0 & 0.3 & 1.5 & 2.5 \\
\hline
\end{tabular}

The efficiency of the proposed experimental platform has been validated using many types of short circuit. Figures 7 and 8 show the interface of Omicron Test Universel used to introduce the parameters of distance protection and elements of protection associated to transmission line.

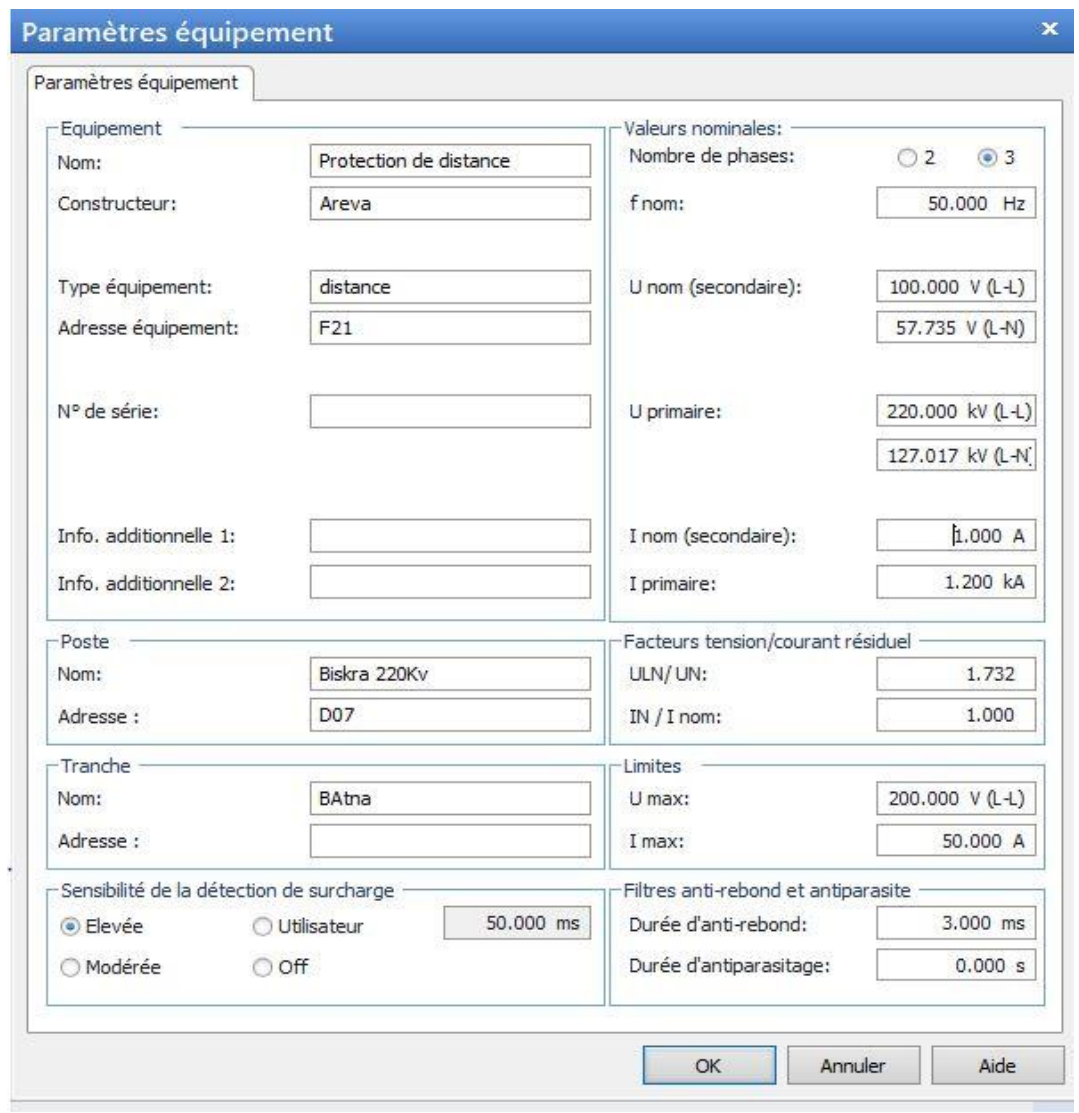

Figure 7. Interface related to configuration of network elements 


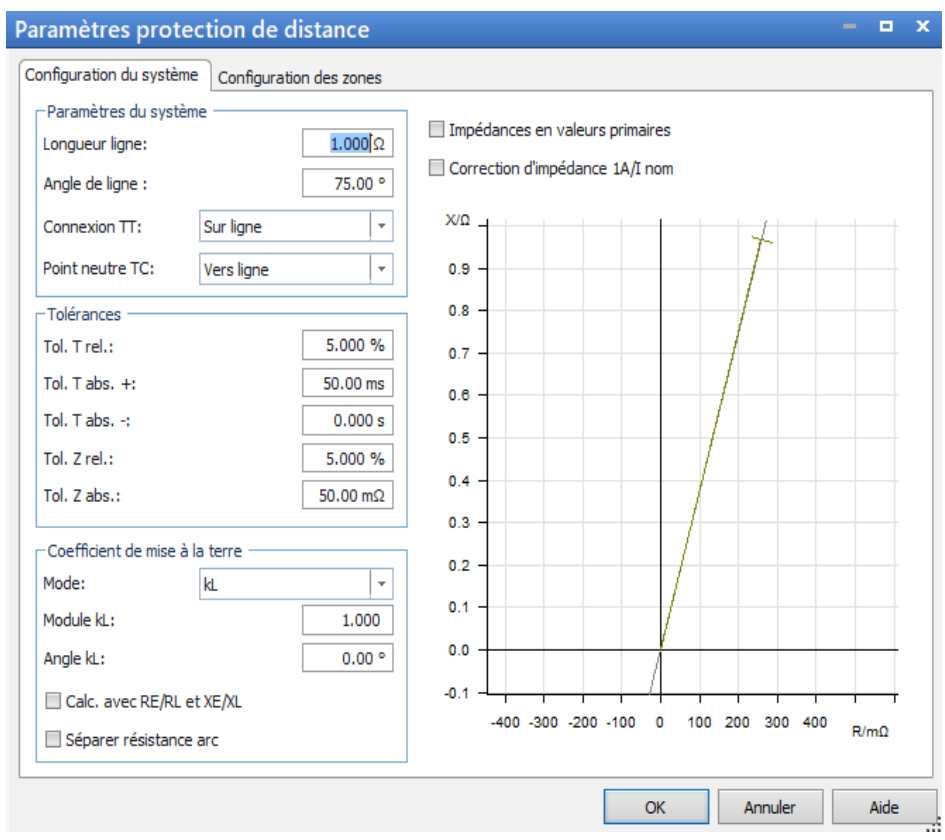

Figure 8. Interface related to parameters configuration of distance protection

\subsection{Test1: Single fault to ground}

To verify the efficiency of the performances of distance protection, a single fault to ground is applied. Table 1, presents the test parameters. After applying the fault, the protection system-based distance relay detects the fault with success at operation time equal $0.25 \mathrm{~ms}$. Figure 9 shows, the experimental results related to the evolution of voltages during three stages, before fault, during fault and after elimination of fault related to zone 1. Figure 10 shows, the variation of fault current for zone1. Figures 11, 12 show the evolution of three voltages and fault current related to zone 2. Figures 13, 14, show the evolution of voltages and fault current related to zone 3, and finally the evolution of voltages and current for single fault to ground associated to zone 4 are shown in Figures 15, 16. Table 2 shows the experimental results of tripping time for single fault to ground. It is well confirmed that the four zones are well coordinated.

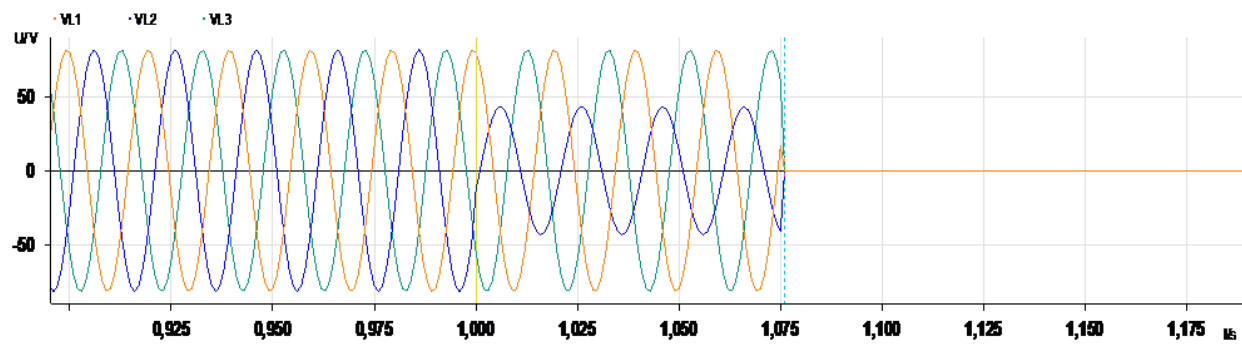

Figure 9. Evolution of three phase voltages during single fault to ground for zone 1

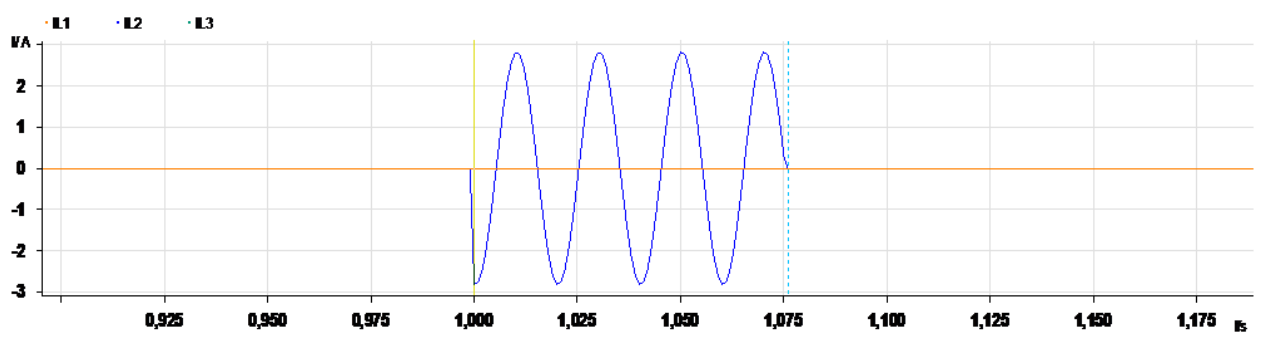

Figure 10. Evolution of current during single fault to ground for zone 1

Experimental platform tests for setting performances of distance protection installed ... (Yassine Khelil) 


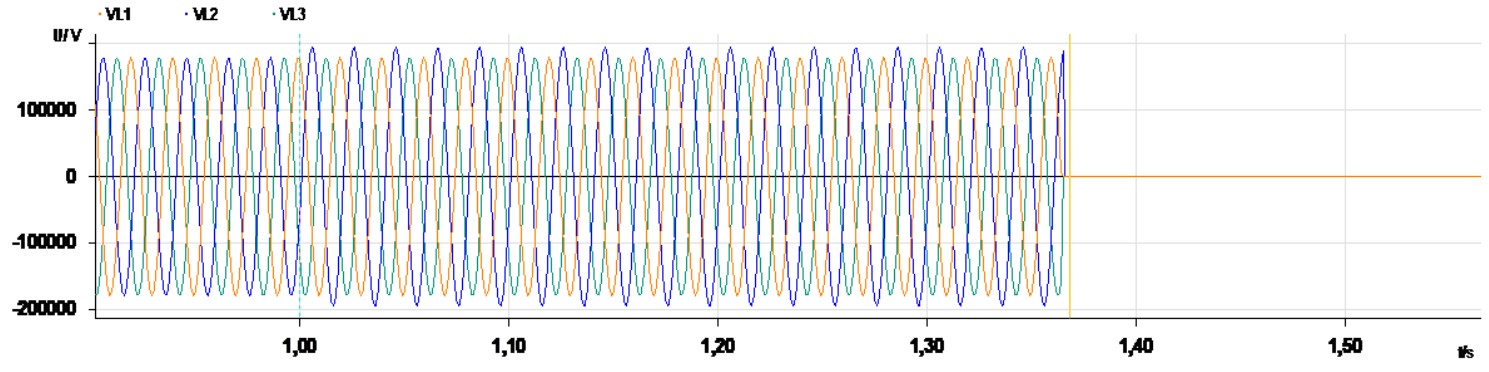

Figure 11. Evolution of three phase voltages during single fault to ground for zone 2

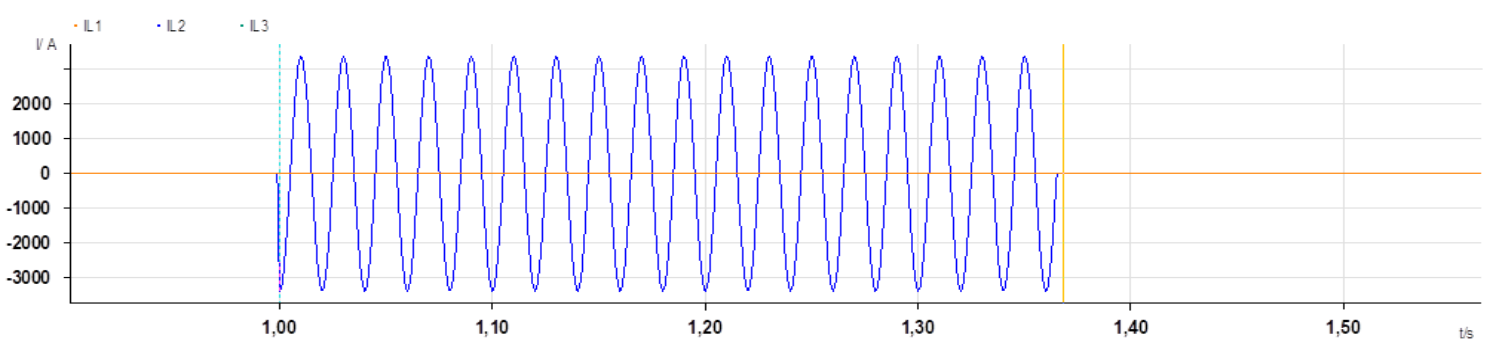

Figure 12. Evolution of current during single fault to ground for zone 2

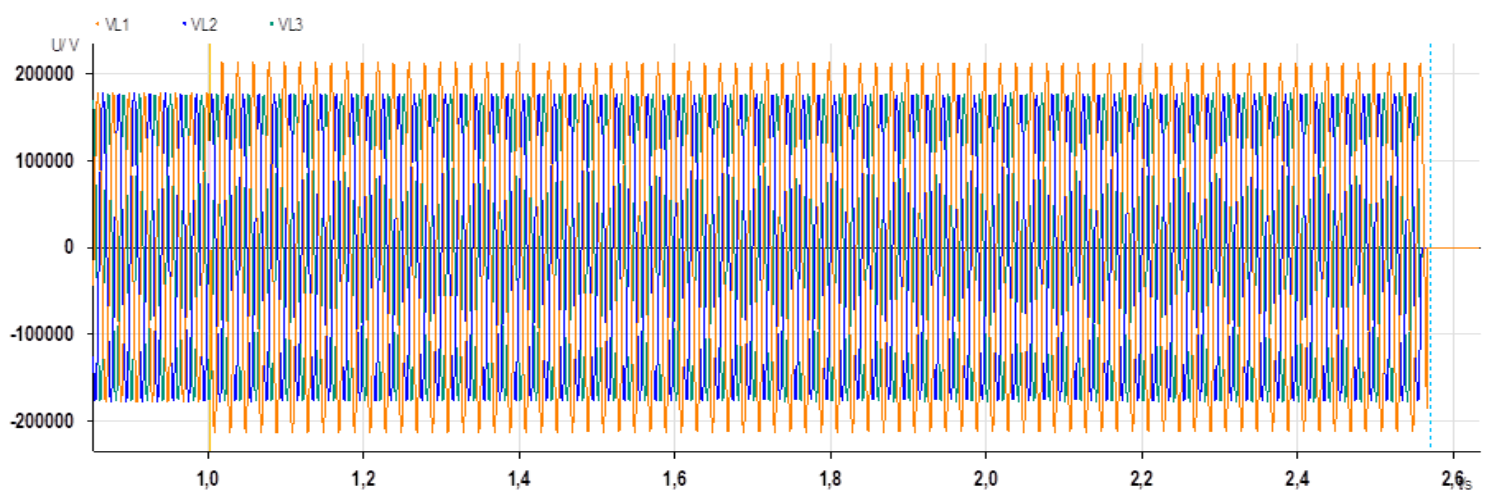

Figure 13. Evolution of three phase voltages during single fault to ground for zone 3

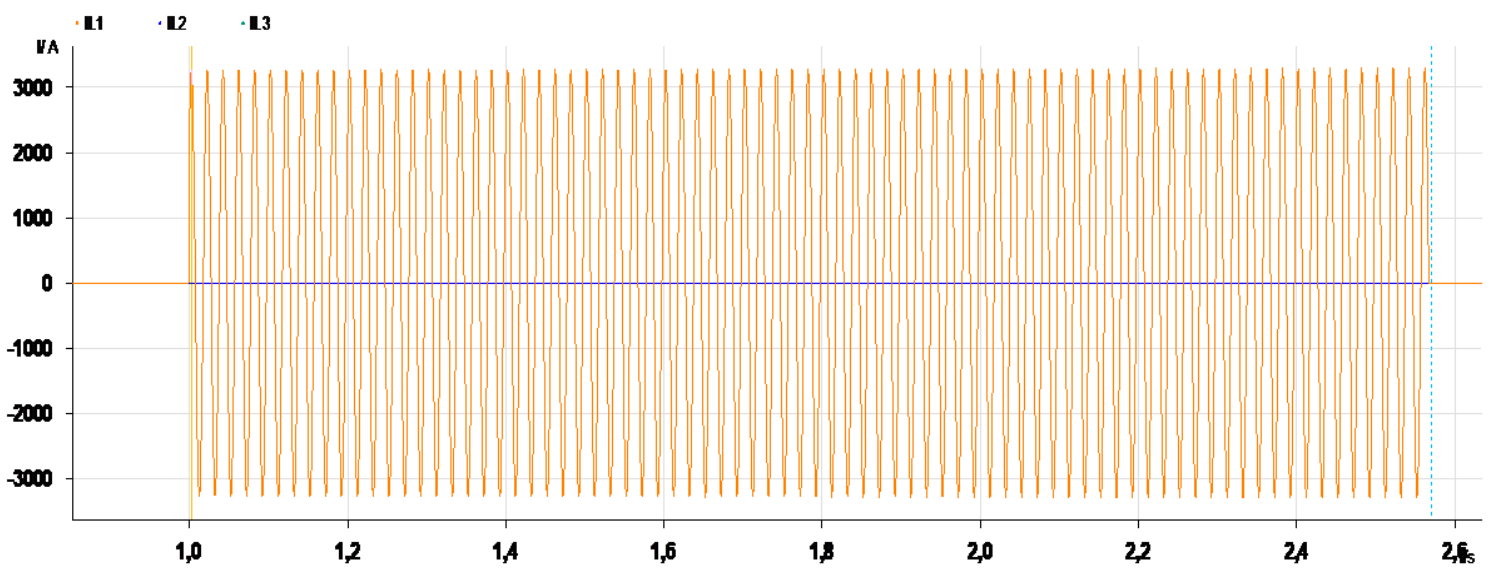

Figure 14. Evolution of current during single fault to ground for zone 3 


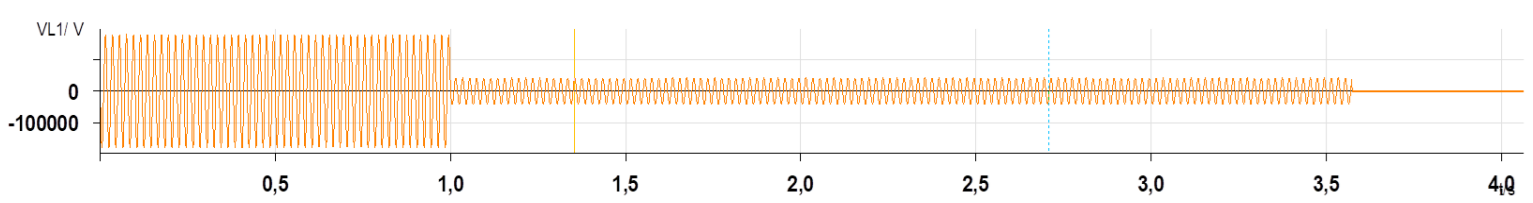

Phase A

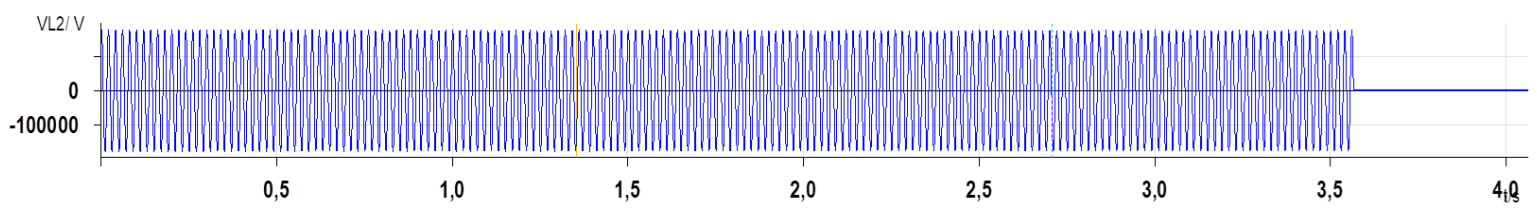

Phase B

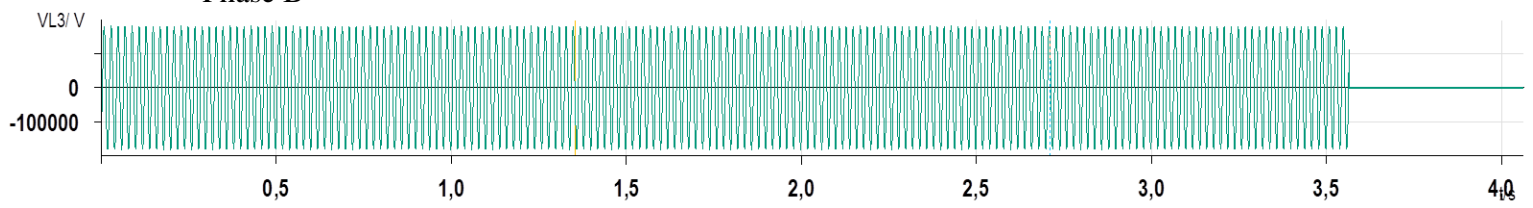

Phase C

Figure 15. Evolution of three phase voltages during single fault to ground for zone 4

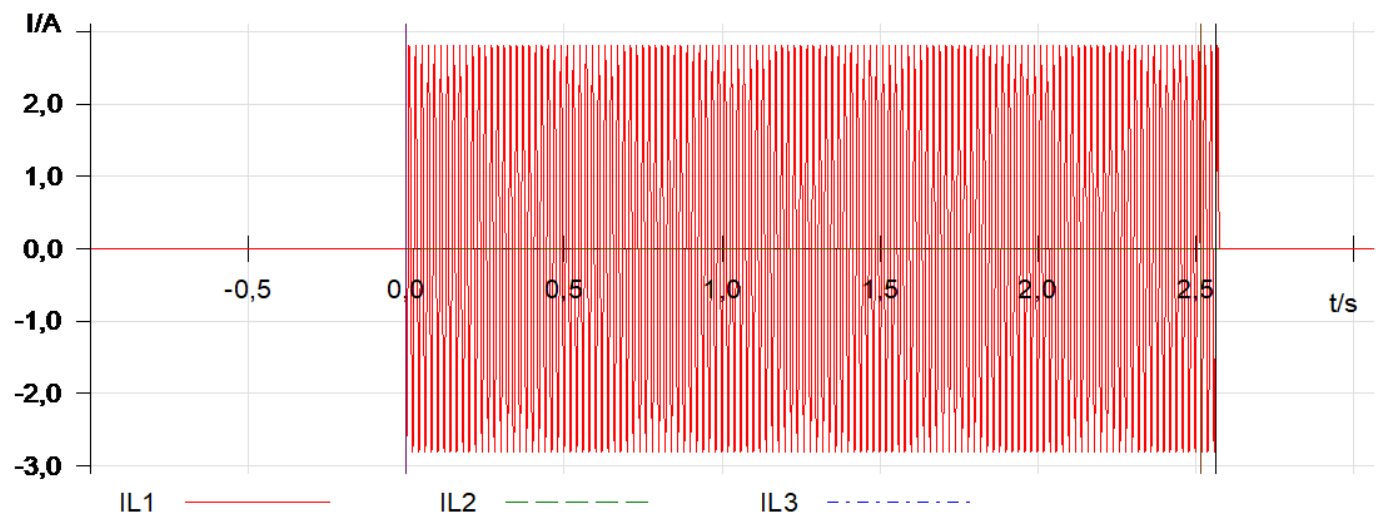

Figure 16. Evolution of current during single fault to ground for zone 4

\subsection{Results interpretations}

The experimental results of tripping time for single fault to ground for the four zones are recapitulated in Table 3 .

- The voltage decreased and the current increased for the faulty phase.

- The measured tripping time is closer to the theoretical value.

- For the single-phase fault in zone 1 and 2, the breaker trips and recloses only for the phase affected, but in zone 3 and zone 4, the breaker trips definitively for the three phases.

Table 3. Experimental results of tripping time for single fault to ground

\begin{tabular}{lcccc} 
& \multicolumn{4}{c}{ Parameters of zones } \\
& Zone 1 & Zone 2 & Zone 3 & Zone 4 \\
\hline $\mathrm{Z}(\Omega)$ & $9.152(\Omega)$ & $18.79(\Omega)$ & $21.17(\Omega)$ & $4(\Omega)$ \\
Angle $\left(^{\circ}\right)$ & 78.30 & 78.30 & 78.30 & -101.70 \\
Measured time $(\mathrm{s})$ & $25.40 \mathrm{~ms}$ & $310.5 \mathrm{~ms}$ & $1.509 \mathrm{~s}$ & $2.516 \mathrm{~s}$ \\
theoretical time $(\mathrm{s})$ & $0.00 \mathrm{~s}$ & $300 \mathrm{~ms}$ & $1.500 \mathrm{~s}$ & $2.500 \mathrm{~s}$ \\
\hline
\end{tabular}

\section{CONCLUSION}

In this paper experimental platform tests are developed and elaborated to validate the performances of distance protection Micom P442 installed in Biskra-Batna transmission line at high voltage station located

Experimental platform tests for setting performances of distance protection installed ... (Yassine Khelil) 
in Biskra. Various faults currents have been performed to verify the selectivity and efficacy of the parameter's settings associated to distance protection. The faults have been created in different locations to verify the setting of time trip of distance protection. Based on various experimental results, it is found that the well coordination of the numeric distance protection has an efficient particularity to detect and eliminate with accuracy the fault at each specified zone; this allows high service continuity to the electric network. Due to the importance of this subject; it will strive to apply an extended version of this experimental platform test to analysis the selectivity of distance protection in the presence of series FACTS devices and several types of renewable sources.

\section{REFERENCES}

[1] H. S. E. Barkat and B. Mahdad, "An experimental educational platform based arduino-GSM for power system protection," 2018 International Conference on Communications and Electrical Engineering ICCEE, El Oued, Algeria, 2018, pp. 1-6, doi: 10.1109/CCEE.2018.8634537.

[2] M. Kezunovic, Y. Q. Xia, Y. Guo, C. W. Fromen and D. R. Sevcik, "Distance relay application testing using a digital simulator," in IEEE Transactions on Power Delivery, vol. 12, no. 1, pp. 72-82, Jan. 1997 , doi: $10.1109 / 61.568227$.

[3] C.-H. Kim, J.-Y. Heo and R. K. Aggarwal, "An enhanced zone 3 algorithm of a distance relay using transient components and state diagram," in IEEE Transactions on Power Delivery, vol. 20, no. 1, pp. 39-46, Jan. 2005, doi: 10.1109/TPWRD.2004.837827.

[4] K.-H. Tseng, W.-S. Kao and J.-R. Lin, "Load model effects on distance relay settings," in IEEE Transactions on Power Delivery, vol. 18, no. 4, pp. 1140-1146, Oct. 2003, doi: 10.1109/TPWRD.2003.817507.

[5] A. Sharafi, M. S.-Pasand and S. M. Hashemi, "Improved zone-3 distance protection based on adjacent relays data," International Transactions on Electrical Energy Systems, vol. 29, no. 2, pp. 1-17, 2018, doi: 10.1002/etep.2726.

[6] E. M. Carrasco, M. P. C. Moreno, M. T. V. Martínez and S. B. Vicente, "Improved faulted phase selection algorithm for distance protection under high penetration of renewable energies," Energies, vol. 13, no. 3, pp. 1-19, 2020, doi: 10.3390/en13030558.

[7] H. Saad, M. Mehanna and E.-S. Osman, "Distance protection relay performance enhancement through integrated control system," Journal Of Al Azhar University Engineering Sector, vol. 14, no. 52, pp. 938-945, 2019, doi: 10.21608/auej.2019.43472.

[8] A. H. Ahmed and A. J. Sultan, "A new approach of Mho distance relay for transmission line protection," IOP Conference Series: Materials Science and Engineering, vol. 518, no. 4, pp. 1-15, 2019, doi: 10.1088/1757899X/518/4/042027.

[9] A. A. H. Mohamad and E. G. Ahmed, "Design a fast digital protective relay algorithm for high voltage transmission line," Sudan Engineering Society Journal, vol.60, no. 1, pp-19-22, 2014.

[10] H. S. Mohamed, M. Mehanna, and E.-S. Osman, "Enhancing the performance of distance protection relays using interactive control system," Indonesian Journal of Electrical Engineering and Computer Science, vol. 13, no. 1, pp. 411-419, 2019, doi: 10.11591/ijeecs.v13.i1.pp411-419.

[11] T. A. A. Almuhsen and A. J. Sultan, "Coordination of directional overcurrent and distance relays based on nonlinear multivariable optimization," Indonesian Journal of Electrical Engineering and Computer Science, vol. 17, no. 3, pp. 1194-1205, 2020, doi: 10.11591/ijeecs.v17.i3.pp1194-1205.

[12] C. Sriram and Y. Kusumalatha, "Three zone detection and distance relay co-ordination of power system protection," International Journal of Electrical and Computer Engineering, vol. 11, no. 2, pp. 919-928, 2021, doi: 10.11591/ijece.v11i2.pp919-928.

[13] J. A. G.-C. Cruz, Z. G. Sánchez, G. C. Sánchez, H. H. Herrera, J. I. Silva-Ortega and V. L. M. Díaz, "A mho type phase comparator relay guideline using phase comparison technique for a power system," International Journal of Electrical and Computer Engineering, vol. 11, no. 2, pp. 929-944, 2021, doi: 10.11591/ijece.v11i2.pp929-944.

[14] S. Das, B. K. Panigrahi and P. K. Jaiswal, "Qualitative assessment of power swing for enhancing security of distance relay in a TCSC-Compensated line," in IEEE Transactions on Power Delivery, vol. 36, no. 1, pp. 223-234, Feb. 2021, doi: 10.1109/TPWRD.2020.2975955.

[15] N. A. M. Yusof, Z. Ali and M. Z. A. Ab Kadir, "A review of adaptive overcurrent protection in distribution networks with integration of distributed energy resources," Indonesian Journal of Electrical Engineering and Computer Science, vol. 19, no. 1, pp. 140-148, 2020, doi: 10.11591/ijeecs.v19.i1.pp140-148.

[16] L. Bougouffa and A. Chaghi, "Effect of renewable energy sources integration on the optimal coordination of directional over-current relays in distribution system," International Journal of Applied Power Engineering, vol. 9, no. 3, pp. 250-255, 2020, doi: 10.11591/ijape.v9.i3.pp250-255.

[17] J.-H. Lee, M.-S. Park, H.-S. Ahn, K.-W. Park, J.-S. Oh, S.-G. Jeon, D.-K. Kim and J.-E. Kim, "Method for protection of single-line-ground fault of distribution system with DG using distance relay and directional relay," Journal of Electrical Engineering \& Technology, vol. 15, pp. 1607-1616, 2020, doi: 10.1007/s42835-020-00452-3.

[18] A. Delavari, P. Brunelle and C. F. Mugombozi, "Real-time modeling and testing of distance protection relay based on IEC 61850 Protocol," in Canadian Journal of Electrical and Computer Engineering, vol. 43, no. 3, pp. 157-162, Summer 2020, doi: 10.1109/CJECE.2020.2968404.

[19] E. E. Mansy and M. Y. Dwidar, "Distance relay-based phasor measurements for protection of transmission lines with UPFC," MEJ. Mansoura Engineering Journal, vol. 43, no. 4, pp. 1-8, 2018, doi: 10.21608/bfemu.2020.95705. 